\title{
The application of regenerable sorbents for mercury capture in gas phase
}

\begin{abstract}
M. Antonia Lopez-Anton*, Nuria Fernández-Miranda and M. Rosa Martínez-Tarazona
Instituto Nacional del Carbón (CSIC). C/ Francisco Pintado Fe No 26, 33011, Oviedo, Spain
\end{abstract}

*Corresponding author

Phone: +34985119090

Fax: +34985297662

e-mail: marian@incar.csic.es 


\begin{abstract}
Mercury is a well-known toxic element and flue gas streams emitted from coalfired utilities are one of the largest anthropogenic sources of this element. This study briefly reviews the proposed technologies for reducing mercury emissions from coal combustion, focusing on an emerging process which involves the use of regenerable sorbents, and especially those loaded with novel metals. Among the mercury species formed during coal combustion, elemental mercury is the most difficult to remove from the flue gases due to its low reactivity and insolubility in water. The widespread interest in using regenerable sorbents with metals is due to their potential capability for retaining elemental mercury. With this technology not only can be reached efficiencies of $100 \%$ in the retention of elemental mercury but also is a way to avoid the generation of new wastes loaded with mercury. This study considers the main aspects that must be take into account when developing effective regenerable sorbents for mercury capture, with special attention to sorbents containing noble metals. The characteristics of this process are compared with those of other processes in a more advanced state of development.
\end{abstract}

Keywords: mercury, control, sorbent, regenerable, coal combustion 


\section{Introduction}

Since mercury is a hazardous air pollutant, the control of mercury emissions to the environment has been the focus of increasing interest and there is a growing concern about the need to prevent its toxic effects on the environment and human health. Some of these health hazards include alterations to the nervous system, neurological disorders, kidney and thyroid damage and even death (WHO, 2016).

At present, anthropogenic mercury emissions are not globally regulated. However, several countries and organizations have introduced a series of guidelines and regulations to reduce the mercury emissions from these sources (EPA 2011; Council of UE 2011). Recently, in the Minamata Convention on Mercury, delegates from over 140 countries adopted a new multilateral environmental agreement that addresses several specific human activities which are contributing to widespread mercury pollution. Of these human activities coal combustion was named as a priority requiring urgent action (Jarvis et al. 2015).

Although mercury emissions into the atmosphere come from a large number of human activities, such as, ferrous and nonferrous metal-manufacturing facilities, the chlor-alkali industry, cement production plants and gold mining, coal combustion is the major source of emissions, releasing approximately 474 tons of mercury into the atmosphere every year, compared to around 10 tons from the burning of other fossil fuels (UNEP 2013). Asian countries are the highest contributors to anthropogenic mercury emissions of mercury, accounting for more than $45 \%$ of the global total, whereas the European Union (EU) and North and South America contribute about 20\% (Rallo et al. 2012). Because coal combustion is the main source of energy in China, this country is the largest mercury emitter in the world (Pirrone et al. 2010). As a 
consequence of the rapid economic development of some countries and the growing energy demands of developing and developed countries, mercury emissions from coal burning can be expected to increase in the near future (Pacyna et al. 2010).

With the aim of identifying the possible solutions to this problem, this work briefly reviews the state of the art of mercury control technologies for coal combustion power plants and focus on one in particular: the use of regenerable sorbents loaded with metals.

\section{Mercury control technologies}

The different mercury behavior in coal-fired power plants makes it difficult to generalize in terms of the applicability, effectiveness and costs a unique mercury technology to mercury control. Moreover, any progress made in this field needs to be properly implemented through regulatory and political programs taking into account the social and cost impacts (Jarvis et al. 2014; Seung-Whee 2016, Pacyna et al. 2010; Sundseth et al. 2010). These are the fundamental challenges that must be considered when searching for the best process to control mercury from coal combustion.

The reduction of mercury emissions from coal power plants could be tackled in several ways, some of which might be by using fuels with low mercury concentrations, by cleaning the coal to reduce the content of this element before combustion (LópezAntón et al. 2006; Martinez-Tarazona et al. 1991; Garcia et al. 1994; Toole-O'Neil et al. 1999) or by thermal treatment of coal for removing volatile trace mercury species (up to $89 \%$ ) from the coal prior to combustion (Bland et al. 2008). However the use of coals with low mercury concentration is not considered a realistic approach and no satisfactory results have been obtained from cleaning the coal, mainly because mercury is generally associated with sulfur minerals or organic matter and both types of species are difficult to separate from coal (López-Antón et al. 2006). The most promising 
method of reducing mercury emissions in the pre-combustion stage has been proved to be that of configuring the boilers for reactants capable of oxidizing mercury. An example of this is the addition of bromide species to the boiler (Vosteen et al.(2005); Vosteen et al. 2010; Berry et al. 2007). Efficiencies up to $90 \%$ indicate that bromide compounds effectively oxidized elemental mercury. The advantage of this process is that the oxidized mercury can be physically or chemically captured in fly ash particles, and then be collected by particle control devices, such as electrostatic precipitators (ESP). Oxidized species are also readily solubilized in water in the flue gas desulfurization units (FGD). However, until now the main focus of research and development for reducing mercury emissions from coal combustion has not been precombustion strategies, but rather post-combustion technologies (Figure 1). These technologies can be classified into two groups as explained below:

2.1 A Multi-pollutant control strategy as a co-benefit for controlling mercury emissions.

This option is based on a multi-pollutant control approach that would deliver cobenefits for the control of mercury emissions. In these processes the gas cleaning systems, already installed in power stations, are optimized for simultaneously reducing mercury. Coal combustion releases mercury in oxidised $\left(\mathrm{Hg}^{2+}\right)$, elemental $\left(\mathrm{Hg}^{0}\right)$ or particulate bound (Hgp) forms. As already mentioned, elemental mercury is a species that is difficult to control because of its high volatility and its insolubility in water, and consequently it is generally emitted with the flue gases. The gaseous oxidized mercury species and mercury bound to particles can be retained in the control systems installed for capturing SOx (FGD) and particulate matter (ESP and bag filters (FF)), respectively (Ochoa-González et al. 2011; Abad-Valle et al. 2011). The advantage of FF is that it allows a longer contact time between particles and the flue gas favoring mercury 
capture. Apart from these technologies, if power plants have systems for controlling NOx, specifically selective catalytic reduction (SCR) systems, these can promote the oxidation of mercury facilitating its subsequent capture in FGD or particulate control systems (Fernández-Miranda et al. 2016). With these gas cleaning devices already working in most power plants, mercury capture efficiency may vary between around $10 \%$ and $90 \%$. As expected, the highest values of mercury reduction were attained by plants with all three control systems: DeNOx, ESP or FF and FGD (Pavlish et al. 2010; Pavlish et al. 2003). The point is that, in general these measures are not sufficient and therefore enormous efforts are being made not only to improve their mercury capture performance but also to develop new mercury-specific technologies.

\subsection{Specific mercury removal process from flue gas}

The most commonly used specific technology for mercury capture in coal-fired power plants is the injection of solid sorbents into the flue gas. The sorbent is injected into the gas, generally at the exit of the boiler and before the capture of ashes (ESP or FF). In this case, the mercury interacts with the particles of the sorbent and is removed together with the fly ash particles in the particle control devices. Of the different possible sorbents, zeolites have been employed for mercury retention with satisfactory results (Liu et al. 2010). Their excellent stability at temperatures above $400^{\circ} \mathrm{C}$ in an acidic flue gas environment, make zeolites an excellent choice as mercury sorbent or mercury sorbent support. Leachability studies have also shown that zeolites may be safely disposed of in landfill (Panagiotou et al. 2000; Morency et al. 2000). However, activated carbons are the most mature and commercially available sorbents tested at industrial scale (Pavlish et al. 2003; Sjostrom et al. 2010). In studies carried out at pilot and industrial scale it has been found that a $\mathrm{C} / \mathrm{Hg}$ weight ratio of between 2000 and 
15000 attain mercury removal efficiencies ranging from 25 to 95\% (Pavlish et al. 2010; Pavlish et al. 2003; O'Dowd et al. 2004). It must be also taken into consideration that flue gas composition may cause a problem for mercury removal with sorbent injection, i.e. the presence of $\mathrm{SO}_{3}$ in the flue gas may decrease mercury capture by activated carbons (Sjostrom et al. 2009). Therefore, although it has already been demonstrated that a high efficiency can be reached in mercury capture by the injection of some activated carbons, other problematic issues must be considered before this technology is implemented (Granite et al. 2000; Pflughoeft-Hassett et al. 2009). The most notable are:

i) The high annual costs, mainly due to the high cost of the preparation of the sorbent and especially when they need to be impregnated with sulphur or halogens by chemical adsorption to improve the mercury capture. Recent studies estimate that the cost of using activated carbon to achieve efficiencies of approximately $82 \%$ ranges from $\$ 110,000$ to 150,000 per kg of mercury (Liu et al. 2010).

ii) The impossibility of regenerating the sorbent. Most activated carbons perform with chemical adsorption mechanisms with the subsequent difficulty for regeneration. The adsorption decreases after regeneration of the spent activated carbon due to deactivation of actives sites (Granite et al. 1998). In the case of a sorbent that captures mercury via a physical adsorption mechanism based on a large surface area the sorbent can be regenerated, but only for a limited number of cycles (Granite et al. 2000).

In addition to the two main problems mentioned above, it must be considered that these carbon sorbents are recovered together with fly ashes in the particle control devices and the co-capture of carbon materials undermines the quality of the ashes, which could have be used as a building material. The mixture of carbon adsorbent and fly ashes constitutes a new mercury-contaminated waste that is repeatedly generated and disposed of in landfills. 
An attractive alternative to the injection of conventional solid sorbents is the use of regenerable sorbents. Of these, those impregnated with noble metals have attracted most interest. Theoretically speaking, a sorbent containing a noble metal can retain mercury via amalgamation and can be regenerated an unlimited number of times. An example of the application of sorbents based on mercury-gold amalgamation is the project MerCap ${ }^{\mathrm{TM}}$ (Mercury Control Adsorption Process) (NETL 2006), which was tested in two coal-fired utilities. Unlike the injection of activated carbons, on which numerous studies have been carried out, few have been conducted on regenerable sorbents and the main aim of this study is to review and discuss the most significant.

\section{Regenerable mercury sorbents loaded with noble metals}

Sorbents loaded with noble metals have been extensively employed on a low scale to concentrate gaseous elemental mercury in devices for mercury analysis. The modus operandi for the retention of mercury in coal combustion processes could be based on the same principle. In these devices, mercury is pre-concentrated by amalgamation on a support loaded with a noble metal (silver, gold and platinum). The collector is subsequently heated, releasing the adsorbed mercury, which is finally detected by the specific detector of the equipment. Figure 2 shows an example of the behaviour of a regenerable sorbent loaded with a noble metal that was tested for mercury capture in coal combustion conditions (Rodriguez-Pérez et al. 2011; Rodriquez-Pérez et al. 2013). It can be observed that in the first step the mercury is adsorbed with $100 \%$ efficiency and in the second step, that of regeneration, the mercury/metal amalgam decomposes at temperatures between $400-500^{\circ} \mathrm{C}$, releasing mercury as a gas which leaves the support clean and ready for further mercury capture cycles (Rodriguez-Pérez et al. 2011; Rodriquez-Pérez et al. 2013). 
3.1 Impregnation of the support with noble metals.

As previously mentioned, mercury (in elemental form), may amalgamate with noble metals such as gold, silver, copper, palladium and platinum (in elemental form). However, to effectively these metals can capture mercury it must be taken into consideration the following issues:

1) The concentration of the metals. In studies carried out so far with sorbents containing different amounts of noble metals, no relation was found between mercury retention capacity and the concentration of the metal. Dong et al. (2009) varied the amount of silver from 1.1 to $27.6 \%$ and concluded that the size of the silver nanoparticles and the state of the silver had more influence on mercury capture than the total silver content. Similar conclusions were drawn in other studies (Rodríguez- Pérez et al. 2011; Izquierdo et al. 2011). Rodriguez-Perez et al. (2011) tested a sorbent prepared with an activated carbon impregnated with gold in concentrations varying from 0.05 to $5 \%$. An increase in the gold content of the sorbent was not found to be relevant for mercury capture as they expected. Efficiency and retention capacity were mainly dependent on the distribution and accessibility of the gold particles on the surface of the support. Impregnation with the highest amount of gold (5\%) entailed the formation of large-sized aggregates which in turn reduced the accessibility of mercury From the results obtained it can be concluded that it is necessary an equilibrium between metal content and metal size distribution to obtain a sorbent with optimum performance.

2) The size and distribution of the metals on the support. In light of these findings, some work has been carried out to assess the influence of noble metal distribution on the support. Schaedlich and Schneeberger results reproduced in a patent 
(Schaedlich et al. 1997) concluded that to retain mercury with high degree of efficiency, it is necessary that the noble metal is extended over a large surface area. It was found by Levlin et al. (1999) that the gold and silver in monolayer is effective for mercury retention. Moreover, they inferred that adsorption of mercury on these surfaces was a complicated multiatomic process and that the saturation level of gold and silver thin films varied according to the adsorption temperature and concentration of mercury in the carrier gas. Moreover, a continuous thin gold film can be transformed into a discontinuous film consisting of separated gold islands depending also on the gas composition (Kobiela et al. 2003).

A way to increase the surface area of metals for more effective mass transfer between mercury and the metals is to incorporate the metals in the form of nanoparticles. This method of preparation also reduces the amount of noble metal necessary to impregnate the support, decreasing the cost of the materials. A study where silver nanoparticles were deposited on zeolite through ion-exchange of sodium ions with silver ions, followed by thermal reduction (Liu et al. 2008) showed a higher mercury retention capacity than the conventional activated carbon-based sorbents in real flue gas environment. Gold-nanoparticles can be obtained by methods based on the formation of gold colloids that are then dropped onto a solid support (Önal et al. 2004; Kimling et al. 2006; Tanyakon et al. 2010; Khannaa et al. 2005). Most of these methods are based on the preparation of a colloid in which a gold salt, such as $\mathrm{HAuCl}_{4} \cdot 3 \mathrm{H}_{2} \mathrm{O}$, in the presence of a reducing agent, forms $\mathrm{Au}^{0}$ in a medium that prevents the agglomeration of gold particles. The stabilizers most frequently employed are PVA (polyvinilalcohol), sodium tris-citrate and THPC (tetrakis(hydroxymethyl) phosphonium chloride). In the method that uses PVA, reductants such as $\mathrm{NaBH}_{4}$ or hydrazine and sodium formaldehyde, among others, are necessary for the reduction of 
$\mathrm{Au}^{3+}$ before the impregnation, whereas the methods based on sodium tris-citrate and THPC, the own sodium tris-citrate and THPC act as reductants in controlled conditions. These methods were probed to be very useful methods for depositing nanoparticles of $\mathrm{Au}^{0}(2-5 \mathrm{~nm})$ achieving efficiencies ranging from 30 to $82 \%$ (Rodríguez-Pérez et al. 2011). As an example Figure 3 schematizes and compares two methods of preparation, one that uses PVA as stabilizer and $\mathrm{NaBH}_{4}$ as reductant, while the other uses THPC as both stabilizer and reductant. However the role that the characteristics of the support play in the final gold nano-dispersion is of paramount importance. As will be explained later different kinds of support can be used to prepare the sorbents.

A novel concept for $\mathrm{Au}^{0}$ nanoparticle deposition is that based on the reduction of $\mathrm{Au}^{3+}$ to $\mathrm{Au}^{0}$ by the carbon material itself (Ballestero et al. 2013). The supports evaluated for this procedure were honeycomb monoliths made exclusively of carbon. Gold nanoparticles were deposited by direct reduction of the $\mathrm{Au}^{3+}$ compound onto the carbon material without using other chemicals compounds.

3) The possibility of degradation of the active metal when it is in contact with corrosive gases. The noble metal layer exposure to flue gases, such as $\mathrm{SO}_{2}$ and $\mathrm{HCl}$ present during coal combustion, and heating, may lead to the transformation of aggregates into larger islands of micrometric sizes which could lead to inefficient mercury capture (Nowakowski et al. 1997; Schaedlich et al. 1997; Battistoni et al. 1996). In studies carried out at laboratory and pilot scale by Butz et al. (2000) demonstrated that noble-metal sorbents were severely degraded by certain flue gas components. The loss of metal and the coalescence of crystallites resulted in reduced sorbent capacity. By contrast, Long et al. (1973) showed that a sorbent loaded with silver did not lose its effectiveness in the presence of different concentrations of $\mathrm{SO}_{2}$, $\mathrm{H}_{2} \mathrm{~S}$ and $\mathrm{NO}_{2}$ in regeneration experiments that were carried out at room temperature. 
Similar results have been obtained in more recent studies (Rodríguez-Pérez et al. 2013) performed in a simulated coal combustion atmosphere $\left(\mathrm{O}_{2}+\mathrm{NO}+\mathrm{SO}_{2}+\mathrm{HCl}+\mathrm{CO}_{2}+\mathrm{H}_{2} \mathrm{O}+\mathrm{N}_{2}\right)$. It was found that an activated carbon loaded with $5 \%$ of gold was able to capture mercury with a $100 \%$ efficiency over several cycles of regeneration without degradation. The presence of $\mathrm{SO}_{2}, \mathrm{NOx}, \mathrm{CO}_{2}$ or $\mathrm{O}_{2}$ was also found to have a negligible impact on the mercury retention capacity of a carbon nanotubesilver composite (Luo et al. 2010). Gómez-Giménez et al. (2015) evaluated the effect of the gas composition $\left(\mathrm{CO}_{2}, \mathrm{~N}_{2}, \mathrm{SO}_{2}\right.$ and $\left.\mathrm{O}_{2}\right)$ on a gold/carbon sorbent. The presence of $\mathrm{SO}_{2}$ in the flue gas led to mercury oxidation when gold nanoparticles were present. In this study it was concluded that elemental sulfur was deposited on the sorbent surface because gold nanoparticles are acted as catalysts for the decomposition of $\mathrm{SO}_{2}$. This regenerable sorbent could then be used upstream of the FGD units, because of the retention of $\mathrm{Hg}^{2+}$ in this unit, or downstream of the FGD because of the absence of $\mathrm{Hg}^{2+}$ or the very low concentration of $\mathrm{Hg}^{2+}$ in the absence of $\mathrm{SO}_{2}$.

It should also be considered that although a gas cleaning process using regenerable sorbents can be situated at different locations in a power plant, if this is sited at the end of the cycle (Figure 1), and the power plant is suited with all possible gas cleaning process (DeNOx, particle control devices and FGD), $\mathrm{Hg}^{0}$ will be the mainly specie at this point. Therefore, these sorbents could be used not only in conventional coal combustion plants (pulverized coal combustion plants (Figure 1) or fluidized bed combustion plants), but also in other processes such as oxy-coal combustion, or in natural gas production (Yan et al. 1994).

3.2 Supports for noble metals. 
Most of the sorbents already prepared and evaluated for use in the retention of mercury in gas phase have been tested on two main types of support; inorganic supports and carbon materials (Liu et al. 2010). Among the first category, zeolites are the most extensively used. Zeolites are good supports for mercury capture due to they have a robust and versatile structure, which serves as an excellent interphase for various active species. Through ion exchange, metals can be introduced on zeolites as ions such as copper and silver cations to balance the structural charge. The treated zeolites present high potential for mercury capture with good regenerability. The advantage of using zeolites over carbon-based sorbents is their resistance to acids. However, in general, carbon-based sorbents have a higher mercury retention capacity and their surface chemistry can be easily modified to favour the dispersion of a noble metal (Izquierdo et al. 2011). Moreover, supports based on activated carbons can be effective for the retention of $\mathrm{Hg}^{0}$ and $\mathrm{Hg}^{2+}$ (Rodríguez-Pérez et al. 2013). It has been found that an activated carbon loaded with gold is able to retain $\mathrm{Hg}^{2+}$ on its own carbonaceous support in the presence of chloride and $\mathrm{Hg}^{0}$ by a process of amalgamation (RodríguezPérez et al. 2013). Silver synthesized on the surface of a carbon nanotube achieved total mercury capture at $150^{\circ} \mathrm{C}$ and then its mercury adsorption capacity was restored at $330^{\circ} \mathrm{C}$ by heating (Luo et al. 2010)). Izquierdo et al. (2011) used carbon monoliths with honeycomb structure as supports for gold. As monoliths have the advantage that they can avoid pressure drop when they are used in the fixed bed of a power plant.

\section{Regenerable mercury sorbents loaded with metal oxides}

Most regenerable sorbents are developed by loading them with noble metals by means of the formation of an amalgam, which is the main theme of the present review. However, this review would not be complete without mentioning other types of metals 
and interactions that also allow sorbents to be regenerated. This is the case of some metal oxides deposited on a large surface area support. This type of sorbent has the ability to capture mercury at very high temperatures $\left(200-400^{\circ} \mathrm{C}\right)$, and has been tested for the retention of mercury in gasification processes (Portzer et al. 2004; Poulston et al. 2007). Scala et al. (2013) developed a regenerable sorbent based on manganese oxide impregnated on high surface area $\gamma$-alumina and supported as a thin layer on cordierite honeycomb monoliths. The sorbent showed a good capability for mercury capture up to $300^{\circ} \mathrm{C}$ and was completely regenerated at $500^{\circ} \mathrm{C}$. No decrease in mercury retention capacity over repeated cycles of mercury adsorption/desorption was observed.

\section{Injection of activated carbons versus regenerable sorbents to control mercury} emissions in coal-fired power plants

As already mentioned, the injection of activated carbons upstream of the particle control devices is the most developed technology for mercury capture in coal combustion power plants. Therefore, we cannot end this review without attempting a comparison between the technology reviewed in this paper and the technology most commonly studied. It is not an easy task to compare these two different types of technology because among other factors, the capacity of the each technology for mercury retention is not well illustrated and will depend on the characteristics of the power plant, control systems installed for other pollutants, the type of fuel, the concentration of mercury in the flue gas, etc. What we can try is to compare results from the data available so far. Moreover, some of the limitations of both processes have already been mentioned above.

Table 1 presents the main characteristics of the two processes. Few studies have attempted to compare these two technologies in terms of costs. Dong et al. (2009) 
estimated that for a flue gas containing $10 \mu \mathrm{g} \cdot \mathrm{m}^{-3}$ of $\mathrm{Hg}$ of which $40 \%$ is $\mathrm{Hg}^{0}$, an injection rate in the order of $71 \mathrm{~kg}$ of magnetic zeolite with silver per one million cubic meters of flue gas is sufficient to retain $80 \% \mathrm{Hg}^{0}$. Although this regenerable sorbent has a much smaller surface area than an activated carbon, the results obtained were similar to those achieved with $24 \mathrm{~kg}$ per one million cubic meters of a commercial activated carbon specifically designed for $\mathrm{Hg}^{0}$ capture (Jones et al. 2007; Feeley et al. 2008). If these data are precise, the initial inversion required for the preparation of a regenerable sorbent where expensive noble metals are used to obtain the sorbent will be higher. However, a clear advantage to these regenerable sorbents is that the initial cost can be recovered by using the same sorbent over several cycles. In a preliminary economic study carried out by Rodriguez-Perez et al. (2013) for a regenerable sorbent based on an activated carbon loaded with $5 \%$ of gold, assuming that the sorbent would be employed in a $1200 \mathrm{MW}$ pulverized coal combustion power station equipped with a flue gas desulphurization unit and that the mercury concentration in the flue gas would be $8.6 \mu \mathrm{g} \cdot \mathrm{m}^{-3}$ for a flow rate of $131147 \mathrm{~m}^{3} \cdot \mathrm{h}-1$, it was estimated that the amount of sorbent required to achieve an efficiency of $100 \%$ would be approximately $28 \mathrm{~kg}$.

\section{Conclusion}

Mercury is an element of primary environment concern and numerous efforts are being taken to reduce its emission from coal combustion processes. Although several different technologies are currently being investigated, recent advances seem to indicate that the future trend will be based on technologies that not only retain mercury efficiently but also those that do not produce new wastes contaminated with mercury. Although the use of a regenerable sorbent, and in particular a regenerable sorbent with noble metals, is still at an early stage, studies conducted so far provide a promising basis 
for the future development of these technologies. For these reasons, future studies need to be focussed on the main factors that will affect the viability of regenerable sorbents: the type of support, the dispersion of metals on the support and the presence of acid gases.

\section{Acknowledgments}

The financial support for this work was provided by the projects CTQ2014-58110-R and GRUPIN14-031. The authors thank PCTI Asturias for awarding N. Fernández Miranda a pre-doctoral fellowship.

\section{References}

Abad-Valle P, Lopez-Anton MA, Diaz-Somoano M, Martinez-Tarazona MR (2011) The role of unburned carbon concentrates from fly ashes in the oxidation and retention of mercury. Chem. Eng. J. 174:86-92

Ballestero D, Gómez-Giménez C, García-Díez E, Juan R, Rubio B, Izquierdo MT (2013) Influence of temperature and regeneration cycles on Hg capture and efficiency by structured $\mathrm{Au} / \mathrm{C}$ regenerable sorbents. J Hazard Mater 260:247254

Battistoni C, Bemporad E, Galdikas A, Kaciulis S, Mattogno G, Mickevicius S, Olevano V. (1996) Interaction of mercury vapor with thin films of gold. Appl. Surf. Sci. 103:107-111

Berry M (2007) Mercury Control Evaluation of Calcium Bromide Injection into a PRBFired Furnace with an SCR. Proceedings of the Air Quality VI Conference, Arlington, VA, September 24-27 
Bland AE, Greenwell C, Newcomer J, Sellakumar KM, Carney BA (2008) A novel pathway for mercury removal by thermal treatment of coal. 33rd International Technical Conference on Coal Utilization \& Fuel Systems, Clearwater, FL, June $1-5$

Butz JR, Turchi C, Broderick TE, Albiston J (2000) Options for mercury removal from coal-fired flue gas streams: pilot-scale research on activated carbon, alternative and regenerable sorbents. 17th Int. Pittsburgh Coal Conference

Council of the European Union (2011) Council conclusions: Review of the Community Strategy concerning Mercury, 3075th ENVIRONMENT Council meeting, Brussels, March 14

http://www.consilium.europa.eu/uedocs/cms_data/docs/pressdata len/envir/119867.pdf

Dong J, Xu Z, Kuznicki SM (2009) Mercury removal from flue gases by novel regenerable magnetic nanocomposite sorbents. Environ Sci Technol 43:32663271

Feeley T, O`Palko B, Jones A (2008) Developing mercury control technology for coalfired power plants-from concept to commercial reality. Main Group Chem $7: 169-179$

Fernández-Miranda N, López-Antón MA, Díaz-Somoano M, Martinez-Tarazona MR (2016) Mercury oxidation in catalysts used for selective reduction of NOx (SCR) in oxy-fuel combustion. Chem Eng J 285:77-82

García AB, Vega JMG, Martínez-Tarazona MR, Spears DA (1994) The removal of trace elements from Spanish high rank coals by a selective agglomeration process. Fuel 73:1189-1196 
Gómez-Giménez C, Ballestero D, Juan R, Rubio B, Izquierdo MT (2015) Mercury capture by a regenerable sorbent under oxycoal combustion conditions: Effect of $\mathrm{SO}_{2}$ and $\mathrm{O}_{2}$ on capture efficiency. Chem Eng Sci 122:232-239

Granite EJ, Pennline HW, Hargis RA (1998) Sorbents for mercury removal from flue gas. DOE/FETC/TR-98-01 http://www.osti.gov/scitech/servlets/purl/1165/

Granite EJ, Pennline HW, Hargis RA (2000) Novel sorbents for mercury removal from flue gas. Ind Eng Chem Res 39:1020-1029

Izquierdo MT, Ballestero D, Juan R, García-Díez E, Rubio B, Ruiz C, Pino MR (2011) Tail-end $\mathrm{Hg}$ capture on Au/carbon-monolith regenerable sorbents. J Hazard Mater 193:304-310

Jarvis A, Maag J (2014) Study on EU implementation of the Minamata convention on mercury. Bipro, Garrigues. June 30

Jarvis A, Maag J (2015) Study on EU implementation of the Minamata convention on mercury. Bipro, Garrigues, Final report. March 30

Jones A, Hoffmann J, Smith D, Feeley T, Murphy J (2007) DOE/NETL's phase II mercury control technology field testing program: Preliminary economic analysis of activated carbon injection. Environ Sci Technol 41:1365-1371

Khannaa PK, Gokhalea R, Subbaraoa VVVS, Kasi-Vishwanatha A, Dasa BK, Satyanarayanab CVV (2005) PVA stabilized gold nanoparticles by use of unexplored albeit conventional reducing agent. Mater Chem Phys 92:229-233

Kimling J, Maier M, Okenve B, Kotaidis V, Ballot H, Plech A (2006) Turkevich Method for Gold Nanoparticle Synthesis Revisited. J Phys Chem B 110:1570015707

Kobiela T, Nowakowski B, Dus R (2003) The influence of gas phase composition on the process of Au-Hg amalgam formation. Appl Surf Sci 206:78-89 
Levlin M, Ikavalko E, Laitinen T (1999) Adsorption of mercury on gold and silver surfaces. Fresenius J Anal Chem 365:577-586

Liu Y, Bisson TM, Yang H, Xu Z (2010) Recent developments in novel sorbents for flue gas clean up. Fuel Process Technol 91:1175-1197

Liu Y, Kelly DJA, Yang H, Lin CCH, Kuznicki SM, Xu Z (2008) Novel regenerable sorbent for mercury capture from flue gases of coal-fired power plant. Environ Sci Technol 42:6205-6210

Long SJ, Scott DR, Thompson RJ (1973) Atomic absorption determination of elemental mercury collected from ambient air on silver wool. Anal Chem 45:2227-2233

López-Antón MA, Díaz-Somoano M, García AB, Martínez-Tarazona MR (2006) Evaluation of mercury associations in two coals of different rank using physical separation procedures. Fuel 85:1389-1395

Luo G, Yao H, Xu M, Cui X, Chen W, Gupta R, Xu Z (2010) Carbon nanotube-silver composite for mercury capture and analysis. Energy and Fuels 24:419-426

Martínez-Tarazona MR, García AB (1991) Trace elements removal during coal cleaning by froth flotation. In: Elemental analysis of coal and by-products. World Scientific 295-298.

Morency JR, Panagiotou T, Senior CL (2000) Laboratory duct injection of a zeolitebased mercury sorbent. Proceedings of the 93rd Air \& Waste Management Association Annual Conference and Exhibition, Salt Lake City, Utah, June 1822

National Energy Technology Laboratory (NETL) (2006) Mercury Emissions Control Technologies: Evaluation of MerCAP for Power Plant Mercury Control. http://www.netl.doe.gov/technologies/coalpower/ewr/mercury/controltech/merca p.htm 
Nowakowski R, Kobiela T, Wolfram Z, Duces R (1997) Atomic force microscopy of $\mathrm{Au} / \mathrm{Hg}$ alloy formation on thin Au films. Appl Surf Sci 115:217-231

O’Dowd WJ, Hargis RA, Granite EJ, Pennline HW (2004) Recent advances in mercury removal technology at the National Energy Technology Laboratory. Fuel Process Technol 85:533-548

Ochoa-González R, Córdoba P, Díaz-Somoano M, Font O, López-Antón MA, Leiva C, Martínez-Tarazona MR, Querol X, Pereira CF, Tomás A, Gómez P, Mesado P (2011) Differential partitioning and speciation of $\mathrm{Hg}$ in wet FGD facilities of two Spanish PCC power plants. Chemosphere 85(4):565-570

Önal Y, Schimpf S, Claus P (2004) Structure sensitivity and kinetics of D-glucose oxidation to D-gluconic acid over carbon-supported gold catalysts. J Catal 223:122-133

Pacyna EG, Pacyna JM, Sundseth K, Munthe J, Kindbom K, Wilson S et al (2010) Global emission of mercury to the atmosphere from anthropogenic sources in 2005 and projections to 2020. Atmos Environ 44:2487-2499

Pacyna JM, Sundseth K, Pacyna EG, Jozewicz W, Munthe J, Belhaj M. et al (2010) An Assessment of Costs and Benefits Associated with Mercury Emission Reductions from Major Anthropogenic Sources. J Air Waste Manage 60:302315

Panagiotou T, Morency JR, Senior CL (2000) Zeolite-based mercury sorbent-laboratory testing and modeling. Prepr DiV Fuel Chem Am Chem Soc. 45:426-430

Pavlish JH, Hamre LL, Zhuang Y (2010) Mercury control technologies for coal combustion and gasification systems. Fuel 89:838-847 
Pavlish JH, Sondreal EA, Mann MD, Olson ES, Galbreath KC, Laudal DL, Benson SA (2003) Status review of mercury control options for coal-fired power plants. Fuel Process Technol 82:89-165

Pflughoeft-Hassett DF, Hassett DJ, Buckley TD, Heebink LV, Pavlish JH (2009) Activated carbon for mercury control: Implications for fly ash management. Fuel Process Technol 90:1430-1434

Pirrone N, Cinnirella S, Feng X, Finkelman RB, Friedli HR, Leaner J, Mason R, Mukherjee AB, Stracher GB, Streets DG, Telmer K (2010) Global mercury emissions to the atmosphere from anthropogenic and natural sources, Atmos Chem Phys 10:5951-5964

Portzer JW, Albritton JR, Allen CC, Gupta RP (2004) Development of novel sorbents for mercury control at elevated temperatures in coal-derived syngas: results of initial screening of candidate materials. Fuel Process Technol 85:621-630

Poulston S, Granite EJ, Pennline HW, Myers CR, Stanko DP, Hamilton H, Rowsell L,

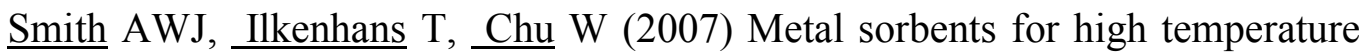
mercury capture from flue gas. Fuel 86:2201-2203

Rallo M, López-Antón M, Contreras ML, Maroto-Valer MM (2012) Mercury policy and regulations for coal-fired power plants. Environ Sci Pollut R 19:1084-1096

Rodríguez-Pérez J, López-Antón MA, Díaz-Somoano M, García R, Martínez-Tarazona MR (2011) Development of Gold Nanoparticle-Doped Activated Carbon Sorbent for Elemental Mercury. Energ Fuel 25:2022-2027

Rodríguez-Pérez J, López-Antón MA, Díaz-Somoano M, García R, Martínez-Tarazona MR (2013) Regenerable sorbents for mercury capture in simulated coal combustion flue gas. J Hazard Mater 260:869-877 
Scala F, Anacleria C, Cimino S (2013) Characterization of a regenerable sorbent for high temperature elemental mercury capture from flue gas. Fuel 108:13-18

Schaedlich FH, Schneeberger DR (1997) Cartridge for Collection of a Sample by Adsorption onto a Solid Surface. US Patent 566079

Seung-Whee R (2016) Control of mercury emissions: policies, technologies and future trends. J Energ Emis Control Technol 4:1-15

Sjostrom S, Dillon M, Donnelly B, Bustard J, Filippelli G, Glesmann R, Orscheln T, Wahlert S, Chang R, O'Palko A (2009) Influence of SO3 on mercury removal with activated carbon: Full-scale results. Fuel Process Technol 90:1419-1423

Sjostrom S, Durham M, Bustard CJ, Martin C (2010) Activated carbon injection for mercury control: Overview. Fuel 89:1320-1322

Sundseth K, Pacyna JM, Pacyna EG, Munthe J, Belhaj M, Astrom S (2010) Economic Benefits from Decreased Mercury Emissions: Projections for 2020. J Cleaner Production 18:386-394

Tanyakorn M, Noriaki S, Shin-Ichi Y, Nawin Viriya VE, Tawatchai C (2010) Facile strategy for stability control of gold nanoparticles synthesized by aqueous reduction method. Curr Appl Phys 10:708-714

Toole-O'Neil B, Tewalt SJ, Finkelman RB, Akers DJ (1999) Mercury concentration in coal unraveling the puzzle. Fuel 78:47-54

UNEP (2013) Global Mercury Assessment 2013: Sources, Emissions, Releases and Environmental Transport. UNEP Chemicals Branch, Geneva, Switzerland

United States Environmental Protection Agency (EPA) (2011) National Emission Standards for Hazardous Air Pollutants from Coal- and Oil-fired Electric Utility Steam Generating Units and Standards of Performance for Fossil-Fuel-Fired Electric Utility, Industrial-Commercial-Institutional, and Small Industrial- 
Commercial-Institutional Steam Generating Units.

http://www.epa.gov/airquality/powerplanttoxics/pdfs /proposal.pdf.

Vosteen B, Beyer J, Bonkhofer T, Kanefke R, Nolte M et al. (2005) Process for Removing Mercury from Flue Gases. Patent application EP1386655 (A1) or patent DE 10233173 or US Patent \# 6,878,358 B2

Vosteen BW, Winkler H, Berry MS (2010) Native halogens in coals from USA, China and elsewhere: Low chlorine coals need bromide addition for enhanced mercury capture. Air and Waste Management Association 8th Power Plant Air Pollutant Control Mega Symposium 2:1174-1242

World Health Organization (WHO) 2016 http://www.who.int/mediacentre/factsheets/fs361/en/

Yan TY (1994) A novel process for Hg removal from gases. Ind Eng Chem Res $33: 3010-3014$ 


\section{Figure captions}

Fig. 1 Control systems of pollutants emitted in a coal-fired power plant with capture of mercury species.

Fig. 2 Typical behaviour of a regenerable sorbent for mercury capture.

Fig. 3 Two methods for gold nanoparticles deposition on carbon supports. 
Table 1. The main characteristics of two specific technologies for elemental mercury retention: injection of activated carbon and regenerable sorbents.

\begin{tabular}{lcc}
\hline & $\begin{array}{c}\text { Injection of activated carbon } \\
(\mathbf{\%})\end{array}$ & $\begin{array}{c}\text { Regenerable sorbents } \\
(\mathbf{\%})\end{array}$ \\
\hline Efficiency & High & High \\
Regenerability & Low or zero & High \\
Resistance to acid gases & High & Medium \\
Impact on sub-products quality & Medium & Zero \\
Generation of wastes & High & Low or zero \\
Cost & Medium-High & High (initial) \\
& & Low (final) \\
\hline
\end{tabular}




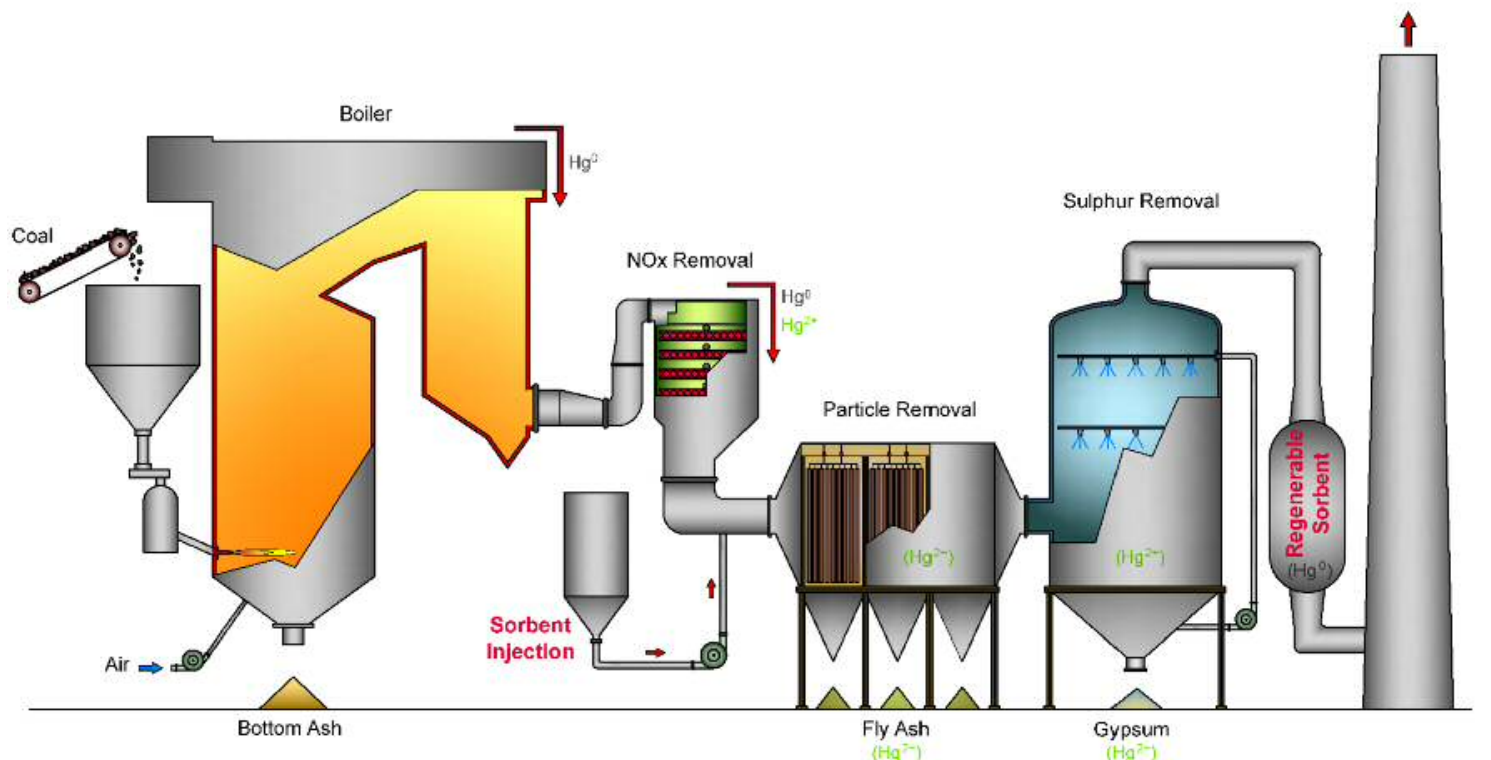

Fig. 1 


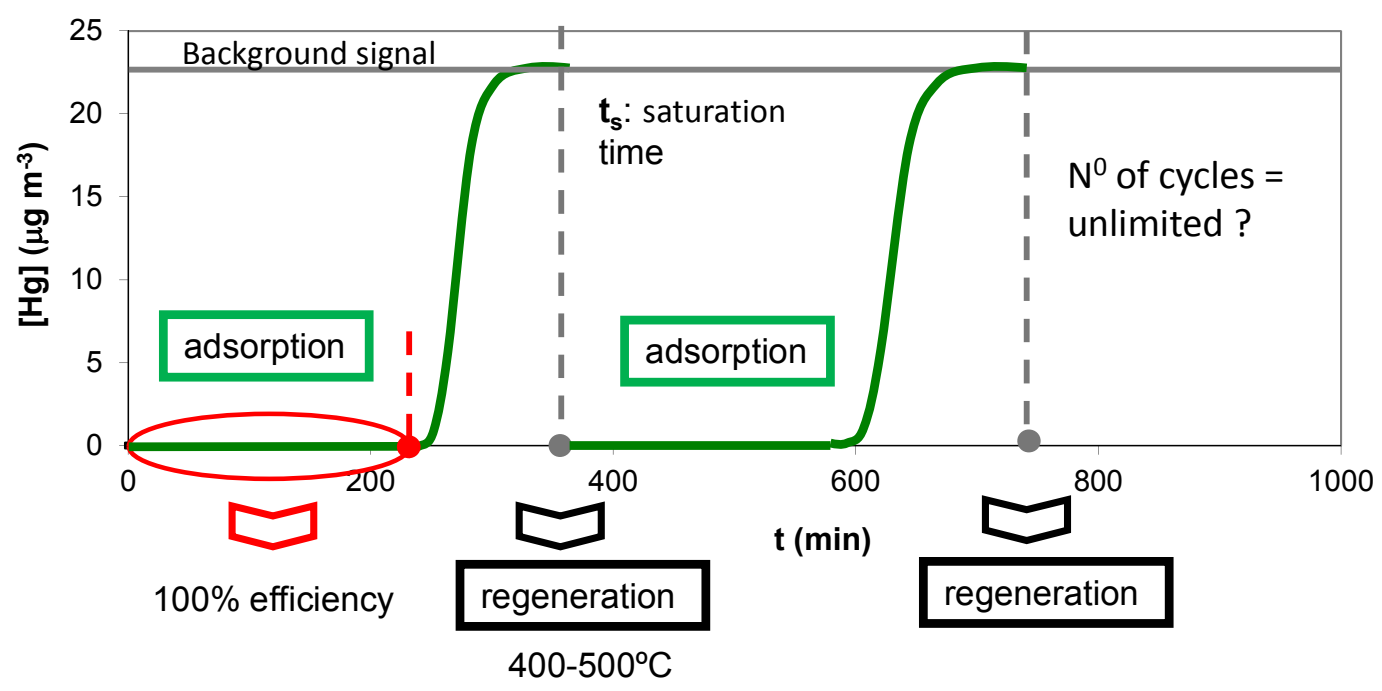

Fig. 2 


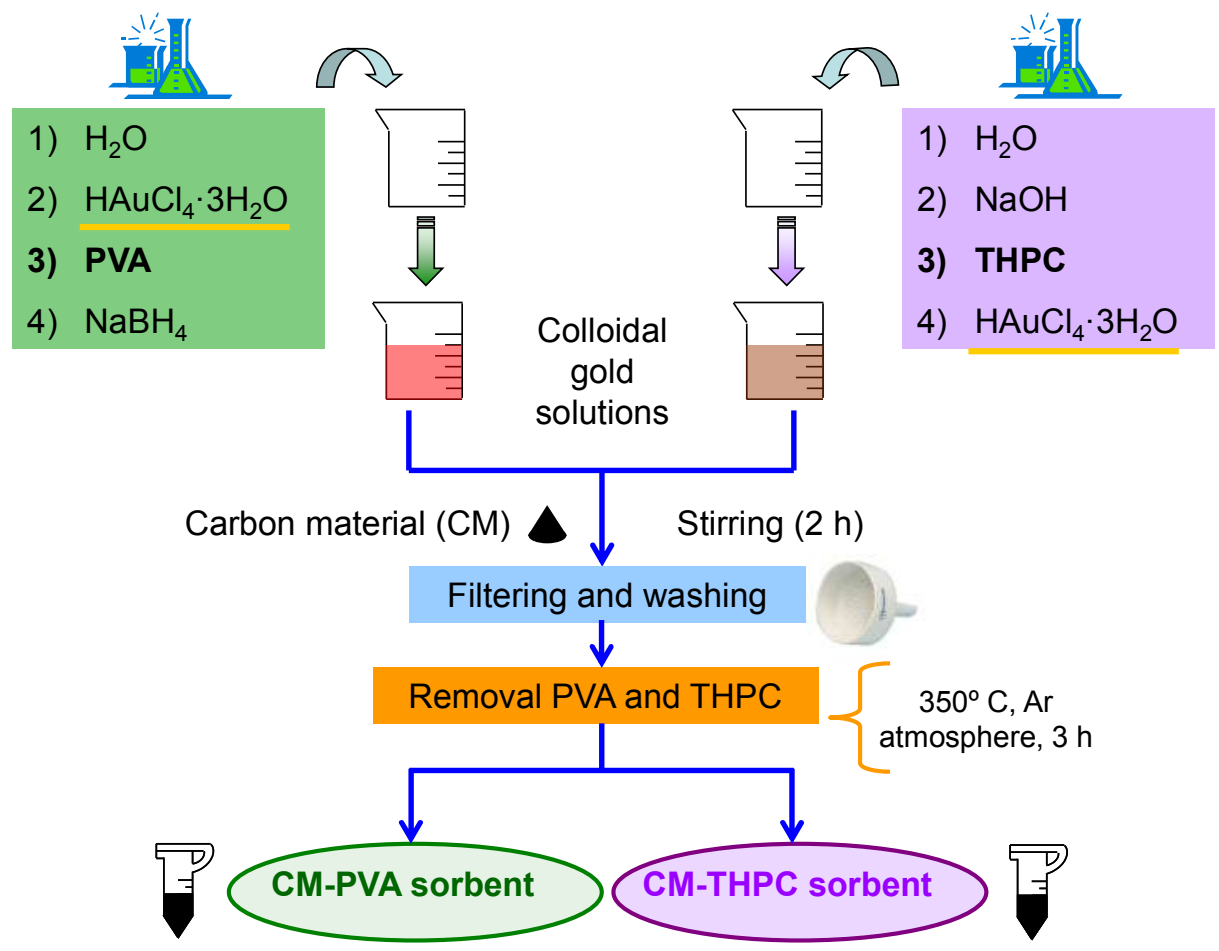

Fig. 3 